\title{
Effects of component training and subsequent sequencing of stimuli on shuttlebox avoidance responding of rats
}

\author{
DONALD J. LEVIS \\ State University of New York at Binghamton, Binghamton, New York 13901 \\ WILLIAM J. DUBIN \\ J. N. Adam Developmental Center, Perrysburg, New York 14129 \\ and \\ ARNOLD D. HOLZMAN \\ State University of New York at Binghamton, Binghamton, New York 13901
}

\begin{abstract}
The serial presentation of two different CSs, with each stimulus having an 8-sec duration $\left(\mathrm{S1}_{\mathrm{g}} / \mathrm{S2}_{\mathrm{g}}\right)$, consistently has resulted in most of the shuttlebox avoidance responses being recorded to the S2 component. Experiment 1 attempted to attenuate this serial CS, delayedresponse effect by conditioning the separate components of a serial CS prior to ordering them sequentially. Ten component-training trials were administered, with subjects receiving CS-US pairing to S1 only, S2 only, or to both S1 and S2 presented on separate trials. Two CS durations $(8$ or $16 \mathrm{sec}$ ) during this phase also were compared. Subjects were then given 100 avoidance test trials using the standard serial procedure. The 10 best avoidance responders in each group were selected for analysis. Shorter avoidance latencies were obtained only for subjects receiving component conditioning to S1. CS duration was not a factor in establishing the shorter latencies. Component conditioning to S2 resulted in increasing the total avoidances. Experiment 2 increased the number of component-training trials and the generality of the findings by using a different strain of rats and by extending the testing phase of the study so that all subjects could be included in the analysis. Comparable results were obtained. The theoretical implications of these data were discussed.
\end{abstract}

In the quest to enhance our knowledge of the laws of S-R connections as they apply to complex environments, various attempts have been made to determine the functional role of individual components comprising a stimulus compound. One strategy sought to enhance the associative strength of individual components by conditioning them separately prior to combining them into a compound (Kamin, 1969; Wagner, 1971). Another approach attempted to provide a careful analysis of response topographies during training to determine whether differential responding to components could be detected (Brahlek, 1968; Levis, 1970). The intent of the present research was to determine the effects of a component-training procedure on modifying the topography of avoidance responding elicited by stimuli ordered in a serial sequence.

Interest in this problem was stimulated by previous research which analyzed the effects of a

Reprint requests should be sent to Donald J. Levis, Department of Psychology, State University of New York, Binghamton, New York 13901.
serial-CS procedure upon shuttlebox-avoidance responding using rats as subjects (Levis, 1970; Levis \& Stampfl, 1972). It was found that when two different CS components (e.g., tone followed by flashing lights) were ordered serially (S1/S2) during training, responding occurred to the CS component closest to the UCS onset. From $60 \%$ to $75 \%$ of the avoidances were recorded during the S2 period. This delay in responding occurred during initial acquisition of shuttlebox avoidance and remained throughout training. It was also noted that the reverse finding was observed with the presentation of a nonserial-CS procedure of equal stimulus duration where the CS pattern (e.g., a tone) remained relatively unchanged during the CS-UCS interval. With the latter procedure, $60 \%$ to $75 \%$ of the avoidance responses were recorded during the first half of the CS-UCS interval.

The stability of the shuttlebox serial-CS finding over trials provides an opportunity for isolating the variables capable of producing a shift in associative strength from the $\mathrm{S} 2$ to the $\mathrm{S} 1$ component. The failure to obtain a substantial associative shift has 
been interpreted as reflecting a transfer decrement across the CS-UCS interval resulting from the stimulus dissimilarity between components. Consistent with this interpretation, two variables have been found to facilitate a shift. Increased responding to the $\$ 1$ component can be enhanced by shortening the length of the CS-US interval (Levis \& Dubin, 1973) or by increasing the stimulus similarity between components (Dubin \& Levis, 1973). It also should be noted that initial differences in avoidance response topographies between serial and nonserial CS procedures are not obtained when a one-way avoidance procedure is used, where the apparatus cues change markedly following a response (Levis, Bouska, Eron, \& Mcllhon, 1970). This latter finding suggests the importanice of analyzing the effects of the contextual environment in which a compound stimulus is embedded.

The strategy adopted in the present research was to enhance the associative strength directly to each component of the serial. This was achieved by training subjects to each component separately prior to ordering them serially. In Experiment 1, the experimental subjects first received 10 training trials, with individual groups being exposed to the S1 alone, the S2 alone, or both the S1 and S2 components presented on separate trials. Two CS-US intervals also were employed during this phase. Following the component-training phase, the $\mathrm{S} 1$ and S2 components were ordered serially for 100 shuttleboxavoidance trials. Of particular interest was whether component training to $\mathrm{S} 1$ would enhance responding to S1 when placed in the context of a serial-CS procedure.

\section{EXPERIMENT 1}

\section{Method}

Subjects and Apparatus. The subjects were selected from a pool of 216 experimentally naive, male Blue Spruce rats reared in the University of Iowa's Department of Psychology colony. They ranged in age at the start of training from 135 to 155 days. Two identical shuttlebox apparatuses housed in separate sound-attenuated chambers were used. Constructed of Plexiglas, each box was $.9 \mathrm{~m}$ long, $12.7 \mathrm{~cm}$ wide, and $25.4 \mathrm{~cm}$ high. Each box was divided into two equal compartments by a $.3-\mathrm{cm}$ Masonite barrier extending $10.2 \mathrm{~cm}$ above the surface of the floor. The floor of each compartment consisted of a grid made of $.3-\mathrm{cm}$ brass welding rods spaced $1.3 \mathrm{~cm}$ apart, center to center. A response was defined as a movement over the barrier from one compartment to the floor of the other. Three pairs of $71 / 2 \cdot \mathrm{W}, 115 . \mathrm{V}$, screw-base lamps which flashed twice per second, a tone (4-KHz sine wave), and shock to the grid floor could be controlled independently for each compartment of each apparatus. Ambient noise level, measured by a General Radio sound-level meter (Model 1551-C), was $57 \pm 1 \mathrm{~dB} \mathrm{SPL}$ (setting C) for both boxes. Measurements were made $5.1 \mathrm{~cm}$ above the grid floor with the microphone being positioned at the midpoint of each compartment. After activation of the tone, the sound level for both boxes increased $10 \pm 1 \mathrm{~dB}$ SPL. The Grason Stadler scrambler shock source (Model 1064GS) for each apparatus was set to produce $1 \mathrm{~mA}$. Avoidance and escape latencies were recorded by a Grason-Stadler printout counter, with resolution of response latencies being obtained to the nearest second. Programming equipment was housed in a separate room. A more complete description of the apparatuses can be found in Levis (1970).

Procedure. Each rat was given a 30 -min adaptation period to the apparatus immediately prior to the start of the first trial. Each subject received 110 consecutive acquisition trials given in a single session. The first 10 trials are referred to as "component-training" trials and the last 100 as "test" trials. A delayed conditioning procedure was used. An escape response terminated both the CS and US, while an avoidance response terminated the CS and prevented US onset. On escape trials, shock remained on until the rat moved to the opposite compartment. The length of the intertrial interval averaged $60 \mathrm{sec}$ (50, 60, $70 \mathrm{sec}$ randomized). The type (tone, flashing lights) and order of CS presentation were counterbalanced within each CS condition. The order of testing subjects was determined randomly.

Experimental conditions. For ease of presentation and for statistical purposes, six of the groups were designated as experimental. For the last 100 acquisition (test) trials, subjects in all six groups received a serial-CS procedure (S1/S2) with a 16-sec CS-US interval. They differed from each other only in the type of component-training trials administered during the first 10 acquisition trials. During these latter trials, two of the groups were presented with only the first component of the serial CS (S1), two were presented with only the second (S2), and two were presented with S1 on half of the trials and S2 on the other half, the order of presentation being randomized (S1, S2). For half the subjects in each of the above three sets of two groups, the CS-US interval was $8 \mathrm{sec}$, and for the other half, the CS-US interval was $16 \mathrm{sec}$. Although the subjects could in principle avoid the US during the component-training phase, previous work had suggested that most subjects fail to avoid during the first 10 acquisition trials. Since a classical fear-conditioning procedure in which responding is not permitted could result in other complications (e.g., acquisition of differential freezing tendencies), the escape-avoidance procedure seemed preferable. As the experimental conditions during the last 100 trials were identical, the six groups will be referred to in terms of the treatment applied during the first 10 trials. Thus, $\left(\mathrm{Sl}_{8}\right)$ is the designation of the group exposed to S1 for an 8-sec CS-US interval during Trials 1-10; Group ( $\left.S 1_{16}, S 2_{16}\right)$ was exposed to $S 1$ and $S 2$ on equal numbers of trials, with a 16-sec CS-US interval.

Baseline conditions. The final three groups were included to provide a baseline against which the obtained effects of the component-training trials of the experimental groups could be evaluated. One group $\left(\mathrm{S}_{\mathrm{s}} / \mathrm{S}_{\mathrm{s}}\right)$, received serial-CS training on Trials 1-10; this group also received serial-CS training on Trials 11-110, as was the case for the experimental groups. The other two groups received no serial-CS training. Group ( $\left.S 1_{8}\right)\left(S 1_{16}\right)$ was exposed to $S 1$ with an 8-sec CS-US interval during Trials 1-10 and to $S 1$ with a 16-sec CS-US interval during Trials 11-110. For Group ( $\left(\mathrm{S1}_{16}\right)\left(\mathrm{S1}_{16}\right)$, the CS-US interval was $16 \mathrm{sec}$ throughout training. (For all groups, the symbols within the first parentheses indicate the conditions during Trials 1-10. Trials 11-110 always employed serial-CS training unless indicated otherwise by a second set of parentheses.)

\section{Results}

Previous research (Brush, 1966; Levis, 1970) found that a considerable percentage of rats tested in a shuttlebox avoidance task under conditions similar to the present study failed to make many avoidance responses. In anticipation of the above finding, each group of the present study was composed of a 
Table 1

Mean Indices for the Test Trials of Experiment 1

\begin{tabular}{|c|c|c|c|c|c|c|}
\hline \multirow[b]{2}{*}{ Group } & \multicolumn{6}{|c|}{ Index (Means $N=10)$} \\
\hline & $\begin{array}{c}\text { Latency of } \\
\text { First } 10 \\
\text { Avoidance } \\
\text { Responses* }\end{array}$ & $\begin{array}{c}\text { Latency of } \\
\text { Total } \\
\text { Avoidance } \\
\text { Responses* }\end{array}$ & $\begin{array}{c}\text { Trial Number } \\
\text { of First } \\
\text { Avoidance } \\
\text { Response } \\
\text { to S1 }\end{array}$ & $\begin{array}{l}\text { Percent of } \\
\text { Avoidance } \\
\text { Response } \\
\text { to S1 }\end{array}$ & $\begin{array}{c}\text { Trial Number } \\
\text { of First } \\
\text { Avoidance }\end{array}$ & $\begin{array}{c}\text { Total } \\
\text { Avoidance } \\
\text { Responses }\end{array}$ \\
\hline $\begin{array}{l}\left(\mathrm{S} 1_{8}\right) \\
\left(\mathrm{S} 1_{16}\right) \\
\left(\mathrm{S} 1_{8}, \mathrm{~S} 2_{8}\right) \\
\left(\mathrm{S} 1_{16}, S 2_{16}\right) \\
\left(\mathrm{S} 2_{8}\right) \\
\left(\mathrm{S} 2_{16}\right)\end{array}$ & $\begin{array}{l}7.6 \\
7.7 \\
8.1 \\
7.7 \\
9.6 \\
9.5\end{array}$ & $\begin{array}{l}8.5 \\
8.4 \\
8.8 \\
8.8 \\
9.8 \\
9.9\end{array}$ & $\begin{array}{l}26.1 \\
16.4 \\
15.1 \\
14.2 \\
18.6 \\
29.6\end{array}$ & $\begin{array}{l}33.1 \\
36.4 \\
28.4 \\
28.1 \\
18.3 \\
16.9\end{array}$ & $\begin{array}{r}13.4 \\
9.1 \\
7.5 \\
6.7 \\
3.3 \\
9.0\end{array}$ & $\begin{array}{l}52.8 \\
44.9 \\
61.4 \\
68.2 \\
75.8 \\
56.6\end{array}$ \\
\hline $\begin{array}{l}\left(S 1_{8} / S 2_{8}\right) \\
\left(\mathrm{Sl}_{8}\right)\left(\mathrm{S1}_{16}\right) \\
\left(\mathrm{S} 1_{16}\right)\left(\mathrm{S1_{16 }}\right)\end{array}$ & $\begin{array}{l}9.7 \\
6.3 \\
5.1\end{array}$ & $\begin{array}{r}10.3 \\
6.7 \\
5.4\end{array}$ & $\begin{array}{r}31.4 \\
8.9 \\
13.7\end{array}$ & $\begin{array}{l}12.0 \\
60.5 \\
70.9\end{array}$ & $\begin{array}{r}10.4 \\
5.9 \\
12.9\end{array}$ & $\begin{array}{l}50.8 \\
51.6 \\
44.4\end{array}$ \\
\hline
\end{tabular}

*In seconds,

relatively large number of subjects $(N=24)$. Twenty-three percent of the rats tested failed to make even one avoidance during the test phase of this experiment (Trials $11-110$ ) and $53 \%$ of the subjects made less than 10 responses. The number of low responders, as defined above, did not differ reliable between conditions. Since latency of avoidance responding is the major dependent measure of this study, a reasonable number of avoidance responses per subject is necessary to adequately assess the effects of the component-training trials. To achieve this objective, the top 10 avoidance responders in each group, as indexed by avoidance during the test phase, were selected for analysis. The mean number of avoidance responses across the truncated groups was 56.3. This method of selecting subjects is in accordance with the recommendations of Spence and Platt (1966).

Component-training trials. As noted earlier, few avoidance responses were expected during the component-training phase of the experiment. Only $3.7 \%$ of Trials $1-10$ produced such a response and $77 \%$ of the subjects analyzed failed to make an avoidance. The mean number of avoidances for those subjects that did respond was 1.6. An analysis of variance was applied to the percent of subjects avoiding in each group, to the number of responses made, and to the mean shock duration received during escape trials. In each case, a nonsignificant effect was found $(F<1)$.

Test trials. Four primary indices of avoidance latencies were analyzed: (1) latency of the first 10 avoidance responses, (2) mean latency of all avoidance responses, (3) trial number of the first avoidance response to $S 1$ (the first $8 \mathrm{sec}$ of the CS-US interval), and (4) percent of avoidance responses to Si. The mean for each index for each group appears in Table 1. The experimental groups were analyzed by a 3 by 2 factorial design with one repeated measure of trials. The between factors consisted of three types of CS condition, defined by which cue was conditioned directly during the componenttraining phase (S1; S1,S2; S2), and two levels of CS duration (8 and $16 \mathrm{sec})$. The experimental groups also will be compared to Group $\left(\mathrm{S1}_{\mathrm{g}} / \mathrm{S} 2_{8}\right)$, the baseline serial-control group.

The first index analyzed, latency of the first 10 avoidances, revealed a reliable CS-condition effect $[F(2,54)=3.5, p<.05]$ and a nonsignificant Duration effect and Condition by Duration interaction. Neither the avoidance trial effect nor interactions with trials were significant. The mean for Group $\left(\mathrm{S1}_{\mathrm{g}} / \mathrm{S} 2_{\mathrm{g}}\right)$ was $9.7 \mathrm{sec}$. A comparison of this control group with each experimental group, using Dunnett's test for comparison with a control (see Edwards, 1963), revealed that Groups $\left(\mathrm{Sl}_{8}\right)$, $\left(\mathrm{Sl}_{16}\right),\left(\mathrm{S} 1_{8}, \mathrm{~S} 2_{8}\right)$, and $\left(\mathrm{S}_{16}, \mathrm{~S} 2_{16}\right)$ reliably $(\mathrm{p}<.05)$ produced faster response latencies.

Analysis of the second index, mean latency of all avoidance responses, also revealed a statistically significant CS-condition effect $[F(2,54)=3.78$, $\mathrm{p}<.05$ ], with the Duration factor and Conditions by Duration interaction being nonsignificant. The mean avoidance response latency for the serial-control group $\left(\mathrm{S}_{8} / \mathrm{S} 2_{8}\right)$ was compared to each of the experimental groups. None of these comparisons was reliable, but the analysis for Groups $\left(\mathrm{Sl}_{8}\right),\left(\mathrm{S1}_{16}\right)$, $\left(\mathrm{S1}_{8}, \mathrm{~S} 2_{8}\right)$, and $\left(\mathrm{S1}_{16}, \mathrm{~S} 2_{16}\right)$ all approached the .05 level $(\mathrm{p}<.10)$.

The third index analyzed, trial number of the first avoidance response to $S 1$, did not reveal any reliable differences between experimental conditions. A comparison of the baseline, serial-control group with each experimental group using Dunnett's test did not produce any reliable differences, aithough the difference between the serial-control group and 
groups $\left(\mathrm{S1}_{16}\right), \quad\left(\mathrm{S1}_{8}, \mathrm{~S} 2_{8}\right)$, and $\left(\mathrm{Sl}_{16}, \mathrm{~S} 2_{16}\right)$ approached significance $(\mathrm{p}<.10)$.

The last latency index analyzed, percent of avoidance responses to $\mathrm{S} 1$, revealed a reliable CScondition effect $[F(2,54)=3.9, p<.05]$, with the Duration and interaction effects being nonsignificant. The mean for the baseline, serial-control group was $12.0 \%$. Experimental groups $\left(\mathrm{Sl}_{8}\right)$ and $\left(\mathrm{Sl}_{16}\right)$ reliably differed from the control group $(\mathrm{p}<.05)$ using Dunnet's test, with Groups $\left(\mathrm{S}_{8}, \mathrm{S2}_{8}\right)$ and $\left(\mathrm{S1}_{16}, \mathrm{S2}_{16}\right)$ only approaching significance $(\mathrm{p}<.10)$.

The experimental conditions also were analyzed on two performance indices, trial number of the first avoidance response, and total avoidance responses. The former index revealed a reliable CS-condition effect $[F(2,54)=4.3, p<.025]$, and a significant Condition by Duration interaction $[\mathrm{F}(2,54)=3.8$, $\mathrm{p}<.05$ ]. Inspection of the respective group means in Table 1 suggests that Group ( $\mathrm{S}_{8}$ ) may be responsible, in part, for the interaction effect. Group $\left(\mathrm{S}_{\mathrm{g}}\right)$ was the only group to respond reliably sooner than Group $\left(\mathrm{S1}_{8} / \mathrm{S}_{8}\right)$, the serial control $(\mathrm{p}<.05)$.

The second index, total avoidance responding, revealed a significant $C S$-condition effect $[F(2,54)$ $=5.3, \mathrm{p}<.011$, while the Duration and the interaction effects were not reliable. Groups $\left(\mathrm{S}_{\mathrm{g}}\right),\left(\mathrm{S1}_{\mathrm{B}}\right.$, $\left.\mathrm{S} 2_{8}\right)$, and $\left(\mathrm{S}_{16}, \mathrm{~S} 2_{16}\right)$ all differed from the baseline, serial-control group ( $p<.05$ in all cases).

Baseline control conditions. To establish the presence of the serial, avoidance-delayed effect, Nonserial-CS Group ( $\left.\mathrm{S1}_{16}\right)$ ( $\mathrm{S1}_{16}$ ) was compared to Serial-CS Group $\left(\mathrm{S1}_{8} / \mathrm{S}_{8}\right)$ on the four avoidance latency indices analyzed for the experimental conditions. Individual group means appear in Table 1. Reliable differences emerged $(p<.01)$ in the expected direction for each of the indices analyzed except for the trial number of the first avoidance response to the first half of the CS-US interval (S1), which only approached significance $(p<.10)$. Reliable differences were not found between these conditions for the performance indices, trial number of the first avoidance response, and total number of avoidance responses.

A comparison also was made between the two nonserial-CS conditions, Groups $\left(\mathrm{Sl}_{8}\right)\left(\mathrm{S}_{16}\right)$ and $\left(\mathrm{S1}_{16}\right)\left(\mathrm{S}_{16}\right)$. Only one statistically significant difference was found for the six indices analyzed. For subjects in Group $\left(\mathrm{Sl}_{8}\right)\left(\mathrm{Sl}_{16}\right)$, the trial number of the first avoidance response was reliably lower $(\mathrm{p}<.025)$.

Analysis of the experimental conditions revealed that CS condition (S1) resulted in the greatest attenuation of the serial, delayed-responding effect. To determine whether the manipulation was powerful enough to produce an avoidance latency distribution comparable to those generated by subjects exposed to the nonserial conditions, a comparison was made over the latency indices between conditions (S1) [Groups $\left(\mathrm{Sl}_{8}\right)$ and $\left(\mathrm{Sl}_{16}\right)$ ] and the two nonserial conditions [Groups $\left(\mathrm{Sl}_{8}\right) \quad\left(\mathrm{Sl}_{16}\right)$ and $\left.\left(\mathrm{Sl}_{16}\right)\left(\mathrm{S1}_{16}\right)\right]$. Statistically reliable differences still emerged with three of these indices: (1) mean avoidance latency $[\mathrm{t}(54)=4.0, \mathrm{p}<.001]$, (2) mean latency of avoidance responding for the first 10 avoidance trials $[\mathrm{t}(54)=2.4, \mathrm{p}<.02]$, and (3) percent of avoidance responding to the first half of the CS-US interval $[\mathrm{t}(54)=5.0, \mathrm{p}<.001]$. In each case, the nonserial-CS conditions showed the superior performance.

Although the type of CS and order of CS presentation were initially appropriately counterbalanced within each group, the selection of only learners resulted in the loss of this control for some of the groups. Inspection of the data suggested that order effects did not interact with any of the latency analyses reported.

\section{EXPERIMENT 2}

The purpose of the second study was to provide a partial replication of Experiment 1. Furthermore, an attempt was made to increase the generality of the finding by using a different strain of rats and by extending the testing phase of the study to 300 trials to insure that all subjects emitted avoidance responses.

\section{Method}

Subjects and Apparatus. The subjects were 24 experimentally naive, male albino rats from the Sprague-Dawley strain raised in the Binghamton laboratory colony. They ranged in age at the start of training from 123 to 170 days. The apparatuses used and stimuli manipulated were identical to those for Experiment 1.

Procedure. Twelve subjects were assigned unsystematically to one of two groups. The procedure used in Experiment 1 for Groups $\left(\mathrm{S1}_{16}\right)$ and $\left(\mathrm{S2}_{16}\right)$ was essentially replicated in the present experiment except for the following changes. Twentyfive, rather than 10 component training trials were given prior to testing. The first 20 trials were classical conditioning trials administered in the left chamber of each apparatus. The CSUS interval was $16 \mathrm{sec}$ with US duration of $1 \mathrm{sec}$. Immediately following the first 20 trials, 5 additional component-training trials were given using the usual escape-avoidance procedure. A classical conditioning escape-avoidance training sequence was adopted because of the increase in the number of componenttraining trials. The aim was to minimize the number of avoidance trials which might occur during this phase.

The procedure followed in the test-training trials was identical to that used in Experiment 1. The only difference was that subjects were given 300 rather than 100 test trials, distributed in 100-trial blocks. These were given on each of three different test sessions separated by approximately $24 \mathrm{~h}$.

\section{Results}

Component-training trials. During the last five training trials, only three avoidance responses were recorded. The mean duration of escape latencies between groups did not differ statistically $(F<1)$. 
Test trials. Four primary indices of avoidance latencies were analyzed: (1) latency of the first 10 avoidance responses, (2) mean latency of all avoidance responses, (3) trial number of the first avoidance response to $\mathrm{Sl}$ (the first $8 \mathrm{sec}$ of the CS-US interval), and (4) percent of avoidance responses to S1.

The first index analyzed, latency of the first 10 avoidance responses, revealed a reliable group effect $[F(1,22)=7.6, p<.025]$ and a nonsignificant Trial effect and Group by Trial interaction. The overall means for Groups $\left(\mathrm{S1}_{16}\right)$ and $\left(\mathrm{S2}_{16}\right)$ were 8.0 and 11.0 , respectively. These data provide a replication of the finding that $S 1$ component-training produces an initial effect of shortening the latency of avoidance responses.

Analyses of indices (2) and (3) did not yield a significant Group effect or Group by Session interaction. The mean avoidance latency for Group $\left(\mathrm{S} 1{ }_{16}\right)$ for Sessions 1,2 , and 3 were 7.0, 9.2, and $11.0 \mathrm{sec}$, respectively. The comparable means for Group (S2 $\left.{ }_{16}\right)$ were 9.5, 10.4, and 11.6, respectively. The effect over sessions was reliable $[F(2,44)=6.6, p<.01]$. The mean trial number of the first $\mathrm{Sl}$ response for Group $\left(\mathrm{Sl}_{16}\right)$ was 24.3 and for Group ( $\left.\mathbf{S} 2_{16}\right)$ was 26.9.

The last latency index analyzed, percent of avoidance responses to $S 1$, revealed a reliable Group effect $[F(1,22)=8.8, p<.01]$, a reliable Session effect $[F(2,44)=5.8, p<.01]$, and a reliable Group by Session interaction $[\mathrm{F}(2,44)=6.0, \mathrm{p}<.01]$. The overall means for Groups $\left(\mathrm{S1}_{16}\right)$ and $\left(\mathrm{S} 2_{16}\right)$ were 30.4 and $9.2 \%$, respectively. A separate analysis over each session revealed a reliable difference between groups for Sessions 1 and $2, p<.01$, with no significant difference being found during Session 3. The mean percent of responding to $S 1$ for Group $\left(\mathrm{S1}_{16}\right)$ on Sessions 1,2 , and 3 was $42.5,34.8$, and 14.0 , respectively. The mean for Group $\left(S 2_{16}\right)$ for each session was $7.9,10.8$, and 8.9 , respectively.

The groups also were analyzed on two performance indices, trial number of first avoidance response and total avoidance responses. The first index produced no reliable difference between groups. The mean of the first avoidance trial for Group $\left(\mathrm{Sl}_{16}\right)$ was 24.7 and for Group $\left(\mathrm{S2}_{16}\right)$ was 26.9. The second index also did not reveal a reliable Group effect, although the difference approached significance $[F(1,22)=3.7, p<.10]$. The overall mean number of avoidance responses for Group $\left(\mathrm{S1}_{16}\right)$ was 72.4 and for Group ( $\left(\mathrm{S} 2_{16}\right)$ was 50.3. It will be recalled that, in Experiment 1 , condition $\mathrm{S} 2$ produced reliably more total avoidances than condition $\mathrm{Sl}$. Although not significant at the .05 level, the finding of the present experiment is in the opposite direction. A breakdown of this index over Sessions 1, 2, 3 revealed for Group $\left(\mathrm{Sl}_{16}\right)$ an avoidance mean of
$58.8,81.9$, and 76.3 responses, respectively, and for Group ( $\left(\mathrm{S} 2_{16}\right)$ a mean of $42.3,49.2$, and 59.3, respectively. The difference noted for Session 2 between groups was significant $[F(1,22)=6.1$, $\mathrm{p}<.025]$. A reliable Session effect also was obtained $[F(2,44)=3.7, p<.05]$, and the Group by Session interaction was found to be nonsignificant.

\section{GENERAL DISCUSSION}

Both experiments found that the mean latency of avoidance responding to a serial CS was shorter and the percentage of avoidances which occurred to S1 was larger for subjects receiving component training of S1. These results suggest that component training of $\mathrm{S} 1$ is an effective procedure for enhancing associative strength of a serial CS, and they are consistent with data obtained from human subjects (Levis \& Levin, 1972). The above findings are in agreement with the generalization hypothesis of fear acquisition outlined by Levis and Stampfl (1972). The separate training of S1 before sequencing should result in the attachment of a higher level of associative strength to this stimulus segment, which, in turn, should result in a greater portion of avoidance responding to this segment when sequenced into a serial CS procedure.

Component training of S2 apparently had little effect on the avoidance latencies of subjects exposed to a serial procedure. However, in Experiment 1, this procedure did produce an increase in the total number of avoidance responses. This latter finding of increased avoidance responding for the component-trained S2 subjects was not replicated in Experiment 2, where a trend toward the opposite result occurred. This difference between experiments may be a function of differences in number of component-training trials given, a variable in need of a more systematic study.

The data reported also may have some implications for Kamin's (1969) interpretation of the "blocking effect" results he obtained with compound CSs. Some aspects of his procedure are analogous to those employed in the present experiments. Using a conditioned suppression paradigm, Kamin first conditioned $\mathrm{S} 1$ and then conditioned S1 and S2 together using a simultaneous compound procedure. He tested in extinction the effects of S1 and S2 separately and found that S2 showed no effects of the conditioning sequence. One of the critical variables responsible for producing the blocking effect on the S2 stimulus was the previous conditioning of $\mathrm{S} 1$ separately before placing this stimulus into the compound. Although the procedures of our experiments differ from those used by Kamin, and although cross-study comparisons of this type are risky, it is still of interest 
to note the effects in the present study on the noncomponent-conditioned stimulus. An extinction test phase is not a necessity in the present study, because the stimuli were ordered serially rather than being placed in a simultaneous compound permitting separate responding to each stimulus.

Using Experiment 1 as an example and avoidance responding as the index of interest, a complete blocking effect was not observed for the noncomponent-conditioned stimulus. The mean number of avoidances made to $\mathrm{S} 2$ for the groups receiving component conditioning to $S 1$ was 32.8 , the mean response to $\mathrm{S} 1$ for condition $\mathrm{S} 2$ was 54.5 , and the mean number made to $S 1$ and $S 2$ for the baseline, serial group was 6.1 and 44.7 , respectively. Avoidance responses were made to both stimuli following component conditioning. The number of avoidances reported for the $\$ 2$ stimulus is a conservative estimate, since any response made to $\mathrm{S} 1$ prevents $\mathrm{S} 2$ from being tested on that trial, reducing the number of test opportunities for the $\$ 2$ component. It would be of interest using the Kamin procedure to determine whether blocking or facilitating effects occur when the stimuli are ordered sequentially.

\section{REFERENCES}

Brahlek, J. A. Conditioned suppression as a function of the number of stimuli that precede shock. Psychonomic Science, 1968, 12, 189-190.

BRush, F. R. On the differences between animals that learn and do not learn to avoid electric shock. Psychonomic Science, 1966, 5, 123-124.
Dubin, W. J.. \& LEvis, D. J. Influence of similarity of components of a serial CS on conditioned fear in the rat. Journal of Comparative and Physiological Psychology, 1973, 85, 304-312.

EDWARDs, A. L. Experimental design in psychological research. New York: Holt, Rinehart \& Winston, 1963.

Kamin, L. J. Predictability, surprise, attention, and conditioning. In B. A. Cambell \& R. M. Church (Eds.), Punishment and aversive behavior. New York: AppletonCentury-Crofts, 1969. Pp. 279-296.

LEVIS, D. J. Serial CS presentation and shuttlebox avoidance conditioning: A further look at the tendency to delay responding. Psychonomic Science, 1970, 20, 145-147.

Levis, D. J., Bouska, S., Eron, J., \& McIlhon, M. Serial CS presentation and one-way avoidance conditioning: A noticeable lack of delayed responding. Psychonomic Science, 1970 , 20. 147-149.

Levis, D. J., \& Dubin, W. J. Some parameters affecting shuttlebox avoidance responding with rats receiving serially presented conditioned stimuli. Journal of Comparative and Physiological Psychology, 1973, 82, 328-344.

LEvis, D. J., \& LeviN, H. S. Escape maintenance under serial and simultaneous compound presentation of separately established conditioned stimuli. Journal of Experimental Psychology, 1972, 95. $451-452$.

LEvis, D. J.. \& Stampfl, T. G. Effects of serial CS presentation on shuttle-box avoidance responding. Learning and Motivation, 1972, 3, 73-90.

SPence, K. W., \& Platt, J. R. UCS intensity and performance in eyelid conditioning. Psychological Bulletin, 1966, 65, 1-10.

W AGNER, A. R. Elementary associaions. In H. H. Kendler \& J. T. Spence (Eds.), Essays in neobehaviorism: A memorial volume to Kenneth $W$. Spence. New York: AppletonCentury-Crofts, 1971. Pp. 187-213.

(Received for publication October 28, 1977; revision accepted February 20, 1978.) 